\title{
Correction to: Efficient in vitro organogenesis, micropropagation, and plumbagin production in Plumbago europaea $\mathrm{L}$.
}

\author{
Mina Beigmohamadi ${ }^{1}$ - Ali Movafeghi ${ }^{1} \cdot$ Samineh Jafari ${ }^{2} \cdot$ Ali Sharafi ${ }^{3,4}$
}

Published online: 23 November 2021

(C) The Society for In Vitro Biology 2021

\section{Correction to: In Vitro Cellular \& Developmental Biology - Plant https://doi.org/10.1007/s11627-021-10224-x}

The name of coauthor Ali Movafeghi was presented incorrectly (as "Movafeghi Ali") in this article as originally published.

The original article has been corrected.

Publisher's note Springer Nature remains neutral with regard to jurisdictional claims in published maps and institutional affiliations.

The original article can be found online at https://doi.org/10.1007/ s11627-021-10224-x.

Ali Movafeghi

movafeghi@tabrizu.ac.ir

$\triangle$ Ali Sharafi

alisharafi@zums.ac.ir

1 Department of Plant Sciences, Faculty of Natural Sciences, University of Tabriz, Tabriz, Iran

2 Department of Pharmacognosy, School of Pharmacy, Zanjan University of Medical Sciences, Zanjan, Iran

3 Zanjan Pharmaceutical Biotechnology Research Center, Zanjan University of Medical Sciences, Zanjan, Iran

4 Department of Pharmaceutical Biotechnology, School of Pharmacy, Zanjan University of Medical Sciences, Zanjan, Iran 